\title{
OPTIMIZING EFFICIENCY OF THE COMBINED SEWER OVERFLOW CHAMBER HOBAS
}

\author{
JiŘí ProcházKa*， JaroslaV Pollert
}

\author{
Czech Technical University in Prague, Faculty of Civil Engineering, Department of Sanitary and Ecological \\ Engineering, Thakurova 7, 16629 Prague, Czech Republic \\ * corresponding author: jiri.prochazka@cvut.cz
}

\begin{abstract}
The paper deals with the design of swinging self-clean screen bars and the assessment of pressure losses in the combined sewer overflow chamber (HOBAS CSO Chamber), sold by the company HOBAS. The HOBAS CSO Chamber ensures a safe transfer of rainwater during a major rain event. The main goal of the research was to determine the pressure losses of the overflow chamber under various conditions - without self-clean screen bars; with screen bars without impurities and with screen bars partially or fully clogged with various impurities. The measurements were performed on a $1: 5$ scale physical model of CSO using 4 probes for measuring level heights. From the measured values, the coefficients of local losses were calculated, which were then entered into the currently used design table of flow capacities of the CSO HOBAC Chamber.

At the same time, the optimal shape of individual rods of swinging self-clean bars was investigated, so that the oscillation of the free ends of the rods supports the separation and self-cleaning function during their operation. The research was conducted on a $1: 1$ scale model, so that impurities present in the CSO during the overflow (i.e. textile, cosmetic handkerchiefs, feminine hygiene products, condoms and others) could be used directly in the measurement. At the end of the experiments, the variants of the rods of screen bars that were the most effective in the separation and self-cleaning function were selected. The self-cleaning effect, which occurs at the end of the rain event and ensures that the CSO is free of impurities and ready for further use, was subsequently tested with the selected variant of the rods.
\end{abstract}

KEYwORDS: Rain separator, physical model, unified sewer system, overflow chamber, pressure losses, environment, CSO Hobas Chamber.

\section{INTRODUCTION}

The main disadvantage of combined overflow chambers (CSO) in general is the direct connection of the sewer system to the recipient. Even if the water flowing into the recipient is severely diluted, it still contains a large amount of pollution. Therefore, this contamination must be pre-cleaned, using a self-cleaning screen bars and an overflow slit. Due to the pre-treatment of coarse impurities, local losses and friction losses occur in these parts of the CSO, which increase with the amount of impurities stuck to the screen bars, or by clogging the overflow slit. Losses are an important aspect in the hydrotechnical calculation of the CSO, so we introduce local loss coefficients and friction loss coefficients. In the case of CSOs, local losses are significant, since a pressure flow occurs in the CSO supply line during the overflow. Clogging of the overflow chamber can lead to a reduction in the outflow of wastewater, an increase in its level and the subsequent undesired heating of objects on the sewer network and outside it. The advantage of the self-cleaning screen bars located on the CSO Hobas Chamber is that the overflow chamber is not completely clogged and subsequently flooded. 1

The CSO Hobas Chamber was developed at the Department of Health and Environmental Engineer- ing of the Faculty of Civil Engineering of the Czech Technical University in Prague in cooperation with the company HOBAS. This CSO places the main emphasis on simple construction, low cost production, easy handling and trouble-free and safe operation. The most suitable location for this type of CSO is a flat area where the inflow pipe can be used as a retention pipe (for this reason, the pipe must be designed as a pressure pipe). As a result, the flow in the CSO is then improved and the primary flush is also captured. The chamber is made of fiberglass, which has minimal wall roughness, and therefore better resists a sedimentation in the CSO. The complete chamber is manufactured in the supplier's assembly room and is imported to the construction site in one piece. Another indisputable advantage is the speed of the installation without technological breaks. [2, 3]

"In principle, the pipe overflow chamber is an assembly of two superimposed pipes, which are interconnected by a slit, which is cut longitudinally below the overflow pipe. With an increased flow, which is not enough to drain the throttling route, the level in the lower tube will increase and after reaching the level of the connecting slit (upper overflow edge), the excess and minimally polluted water is drained to the overflow sewer and further to the recipient. Its 


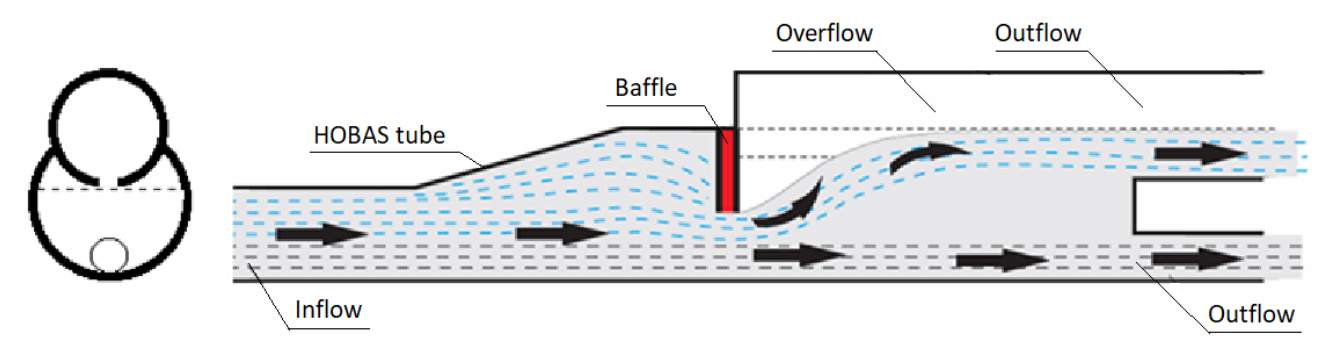

Figure 1. Flow diagram in CSO Hobas chamber.

location at the top of the inlet pipe has the task of improving the cross-flow, which has a positive effect on the separation of undissolved substances. The principle of the mechanical pre-treatment is supported by the existence of the cross-flow when compared with conventional solutions (e.g. side overflow edge), where undissolved substances and sediment swirl and disrupt the natural flow." [4, 5]

\section{MeAsurement of PRESSURE LOSSES}

\subsection{PhysicAl MOdel of HOBAS CSO Chamber}

The Hobas CSO Chamber model was in the Water Management Experimental Center at the CTU Faculty of Civil Engineering. It was made mostly of transparent plastic and PVC pipes in a scale of $1: 5$. 6]

The model is equipped with two KROHNE flowmeters and 4 PEPERL + FUCHS ultrasonic sensors for level measurement during individual measurement states. The Fiedler M4016-G evaluation unit was used to evaluate all probes.

\subsection{Measurement procedure}

To determine the pressure losses, a total of 16 states were measured, each at a 20-minute interval from the minimum flow (i.e. $4.05 \mathrm{l} / \mathrm{s}$ ) at the inflow. This value was chosen so that the water fell tightly. The maximum possible value was chosen $12.90-13.40 \mathrm{l} / \mathrm{s}$. This value is the maximum that the model can hold. In addition, 4 more intermediate stations were measured. 3 different outflow states were set for each inflow, from a fully closed outflow of $0.00 \mathrm{l} / \mathrm{s}$ (simulates a complete clogging of the outflow) to $2.00 \mathrm{l} / \mathrm{s}$ (simulates an approximately half clogging of the outflow) and the last type of outflow is the maximum opening, the value is between $3.75-4.00 \mathrm{l} / \mathrm{s}$ and there is nothing to prevent this outflow.

During each measurement, the values of the individual probes were continuously measured and recorded in the evaluation unit. [6]

The measurement was divided into 4 parts:

- CSO without screen bars

- CSO with non-clogged screen bars

- CSO with the first screen bar clogged

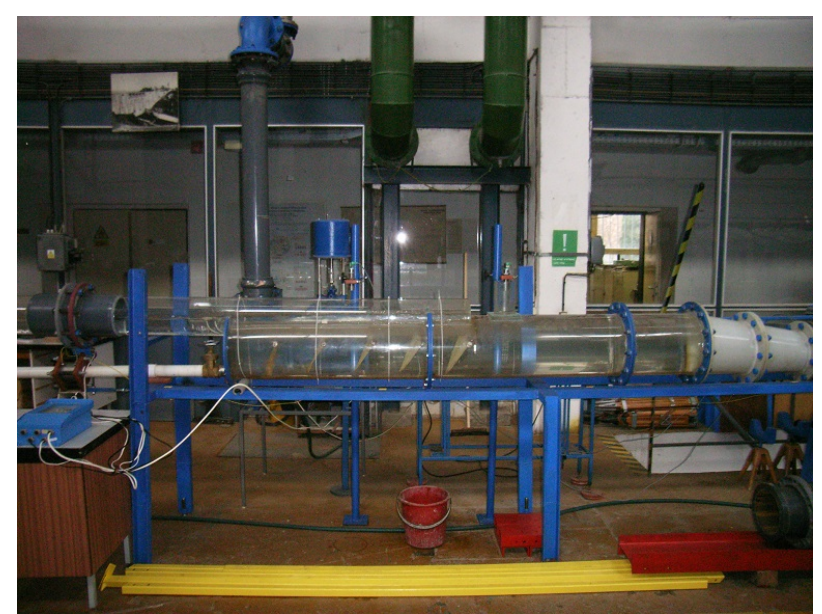

Figure 2. Placement of the model in the laboratory.

- CSO with clogged screen bars

\subsection{RESUlts AND DISCUSSION}

The following placeholder graph (Fig. 4) compares all the results on probe 4 and on probe 1 . These are not values from the measurements, but values that were created using a second-order polynomial curve. In this graph, we can observe the overall trend, which we assumed and that the smallest losses will be measured for the state without screen bars, followed by the state with unclogged screen bars, then with the first screen bar clogged and the largest differences in probes will be measured for the state with all screen bars clogged.

An important point is the calculation of the measured coefficient of local losses and the comparison with table coefficients. All local losses were summed and compared with the measured values. Due to the fact that it was measured in four places on the physical model, it is not possible to divide the values in a same way as the table values and then compare them. Therefore, in the following table, the comparison of the summed values is a coefficient of local losses. The calculation of the local loss coefficient from the measurement was performed from the measured values, where the total losses were found. From the equations above, the local loss coefficient $\xi_{c}$ was calculated for each measurement. An average figure was calculated from these measurements. 

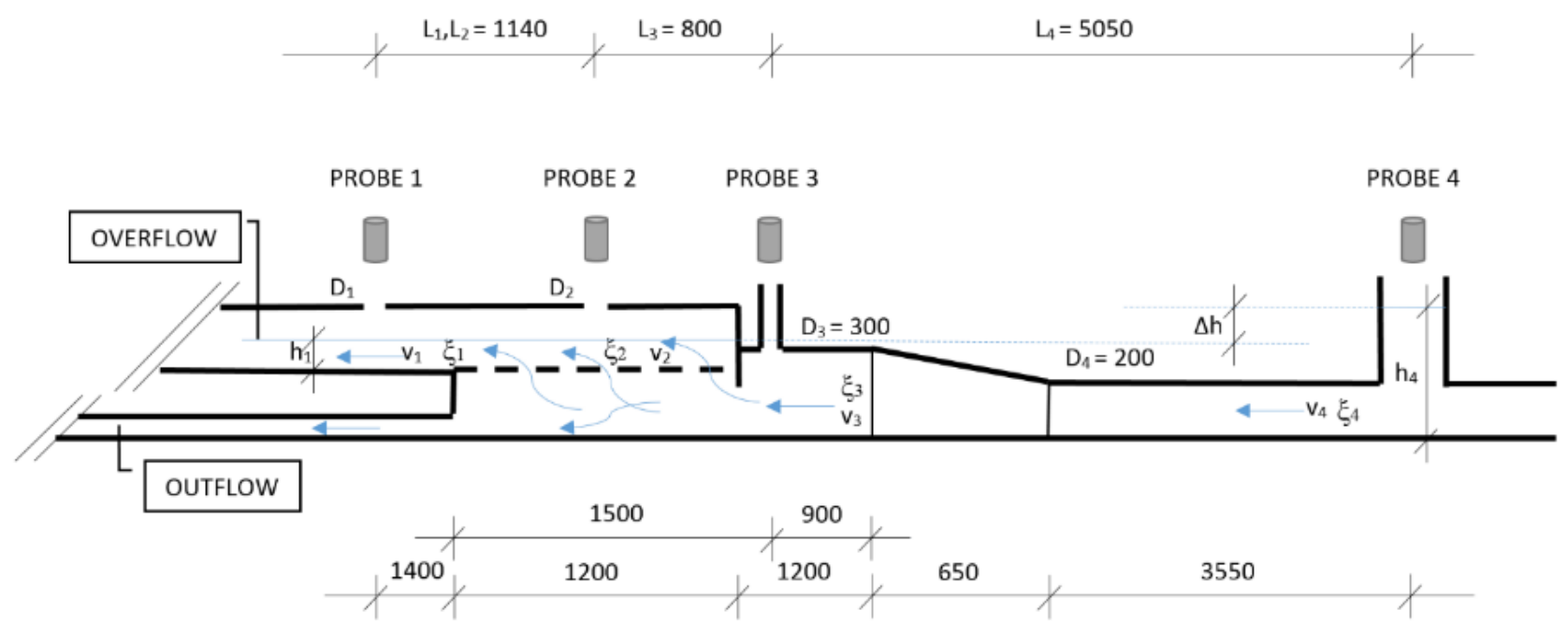

FiguRE 3. Diagram of placement of ultrasonic probes on the model.

\section{Difference between probe 4 and probe 1 depending on overflow (linear series)}

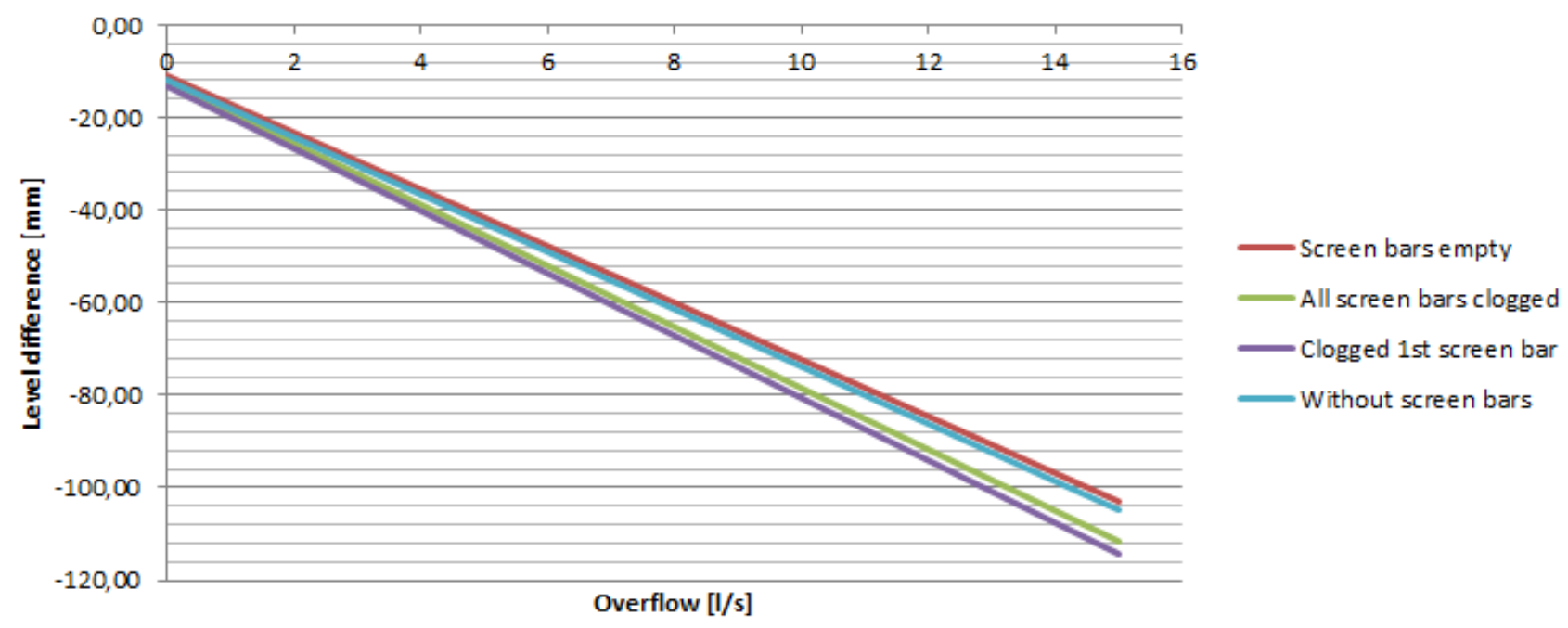

Figure 4. Difference between probe 4 and 1.

\begin{tabular}{ll}
\hline \multicolumn{2}{c}{ Local loss coefficient $\xi$} \\
\hline Without screen bars & 0.731 \\
Screen bars empty & 0.753 \\
Clogged 1st screen bar & 0.797 \\
All screen bars clogged & 0.826 \\
\hline
\end{tabular}

TABLE 1. Local loss coefficient.

Because the losses are speed dependent, we take the speed in the supply line when it is fully filled as a reference value. The pipes are fully filled during the overflow. Friction losses can be local losses due to the relative length in all parts and the low effect of total losses. To calculate the total losses in the CSO, we can use a simplified coefficient of total loss. This coefficient depends on the extent to which the screen bars are clogged. For safety reasons, it is recommended to use the worst-case variant - all screen bars are clogged if the CSO is equipped with screen bars.

The measured coefficients of local losses were then entered into the currently used design table of flow capacities of the CSO Hobas Chamber (Tab. 2), where they replace the original table coefficients.

When designing a new CSO Hobas Chamber, only the information about the original CSO is entered into the design table (length, diameter, etc.), in which the planned CSO variant (without screen bars / with screen bars) is selected and the table calculates the flow capacities of the proposed CSO. The design table, after substituting the coefficients of the detected losses (which correspond much better to the facts than the original table values), optimizes the design of the 


\begin{tabular}{|c|c|c|c|c|c|c|c|c|c|}
\hline Hobas CSO Parts & $\begin{array}{c}\text { Inflow } \\
Q \\
{\left[\mathrm{~m}^{3} / \mathrm{s}\right]} \\
\end{array}$ & $\mathrm{DN}$ & $\begin{array}{c}\text { Radius } \\
r \\
{[\mathrm{~m}]}\end{array}$ & $\begin{array}{c}\text { Depth } \\
h \\
{[\mathrm{~m}]}\end{array}$ & $\alpha$ & $\begin{array}{c}\text { Area } \\
S \\
{\left[\mathrm{~m}^{2}\right]}\end{array}$ & $\begin{array}{c}\text { Surface } \\
\text { width } \\
t \\
{[\mathrm{~m}]}\end{array}$ & $\begin{array}{c}\text { Wetted } \\
\text { perimeter } \\
O \\
{[\mathrm{~m}]} \\
\end{array}$ & $\begin{array}{c}\text { Slope } \\
i \\
{[\% 0]} \\
\end{array}$ \\
\hline Inlet pipe & 2.87 & 1200 & 0.6 & 1.200 & 0 & 1.131 & 0.000 & 3.770 & 2.60 \\
\hline Inflow pipe with free surface & 2.87 & 1200 & 0.6 & 1.200 & 0 & 1.131 & 0.000 & 3.770 & 2.60 \\
\hline Separating chamber & 2.87 & 1600 & 0.8 & 0.770 & 3.07 & 0.957 & 1.599 & 2.453 & 2.60 \\
\hline Baffle & 2.87 & 1600 & 0.8 & & & 1.005 & & 2.513 & 2.60 \\
\hline Without screen bars & 2.87 & 1600 & 0.8 & & & & & & \\
\hline Screen bars - empty & 2.87 & 1600 & 0.8 & & & & & & \\
\hline Clogged 1st screen bars & 2.87 & 1600 & 0.8 & & & & & & \\
\hline All screen bars clogged & 2.87 & 1600 & 0.8 & & & & & & \\
\hline Overflow slit & 2.8 & & & & & 2.160 & & & 2.60 \\
\hline Overflow pipe & 2.8 & 1200 & 0.6 & 0.960 & -1.9 & 0.970 & 0.960 & 2.657 & 2.60 \\
\hline Throttle pipe & 0.07 & 300 & 0.15 & 0.300 & 0 & 0.071 & 0.000 & 0.942 & 2.60 \\
\hline \multirow{2}{*}{ Hobas CSO Parts } & Velocity & & & $\begin{array}{c}\text { Pipe } \\
\text { length }\end{array}$ & $\begin{array}{c}\text { Loss } \\
\text { coefficient }\end{array}$ & Headloss & $\begin{array}{c}\text { Friction } \\
\text { loss }\end{array}$ & $\begin{array}{l}\text { Overall } \\
\text { loss }\end{array}$ & \\
\hline & $\begin{array}{c}v \\
{[\mathrm{~m} / \mathrm{s}]}\end{array}$ & $\triangle / P D$ & $\lambda$ & {$[\mathrm{m}]$} & $\zeta$ & $\begin{array}{l}Z_{m} \\
{[\mathrm{~m}]} \\
\end{array}$ & $\begin{array}{c}Z_{t} \\
{[\mathrm{~m}]}\end{array}$ & {$[\mathrm{m}]$} & {$\left[\mathrm{m}^{3} / \mathrm{s}\right]$} \\
\hline Inlet pipe & 2.538 & 0.000008 & 0.012 & & 0.0000 & & & & 2.58 \\
\hline Inflow pipe with free surface & 2.538 & 0.000008 & 0.012 & 10 & 0.0000 & 0.0000 & 0.0328 & 0.0328 & 2.58 \\
\hline Separating chamber & 2.998 & 0.000006 & 0.013 & 7.2 & 0.0063 & 0.0029 & 0.0268 & 0.0297 & 5.57 \\
\hline Baffle & 2.855 & 0.000006 & 0.01 & & 0.0911 & 0.0378 & 0.0000 & 0.0378 & 5.57 \\
\hline Without screen bars & & & & 7.2 & 0.7311 & 0.2400 & 0.0000 & 0.2400 & $\mathrm{OK}$ \\
\hline Screen bars - empty & & & & 7.2 & 0.7531 & 0.2472 & 0.0000 & 0.2472 & OK \\
\hline Clogged 1st screen bars & & & & 7.2 & 0.7968 & 0.2615 & 0.0000 & 0.2615 & OK \\
\hline All screen bars clogged & & & & 7.2 & 0.8263 & 0.2712 & 0.0000 & 0.2712 & OK \\
\hline Overflow slit & 1.296 & & & & 0.0000 & 0.1185 & 0.0000 & 0.1185 & \\
\hline Overflow pipe & 2.887 & 0.000008 & 0.013 & 7.2 & 0.0000 & & 0.0331 & 0.0331 & 2.58 \\
\hline \multirow[t]{2}{*}{ Throttle pipe } & 0.990 & 0.00003 & 0.011 & 1 & 0.0000 & & 0.0018 & & 0.06 \\
\hline & & & & & & 0.2712 & 0.0927 & 0.2712 & \\
\hline
\end{tabular}

TABle 2. Evaluation and losses in CSO.

new CSO Hobas Chamber. For presentation reasons, the optional CSO variants are all displayed and are marked in yellow (Tab. 2), only the selected variant is shown when calculating the capacity flows.

\section{RESEARCH OF MECHANICAL PROPERTIES OF SWINGING \\ SELF-CLEANING SCREEN BARS}

\subsection{PhysicAl MODEL OF SELF-CLEANING SCREEN BARS}

In this part, the research follows up on the issue of mechanical properties of intelligent swinging selfcleaning screen bars for the CSO HOBAS Chamber.

The physical model for the research was designed so that it was possible to test the self-cleaning screen bars at a scale of $1: 1$ using real aesthetic pollution and velocity flow, which is common in the sewer system. Therefore, the model was designed so that it can be narrowed to the required width at any time and thus ensure high flow velocities $(1-2 \mathrm{~m} / \mathrm{s})$. It was important to ensure that the construction of the screen bars supports the self-cleaning effect of the swinging screen bars and their individual rods, mechanical resistance and frost resistance. After considering the available materials, the drawn composite materials from the company PREFA KOMPOZITY, a.s. [1, 7] were chosen.

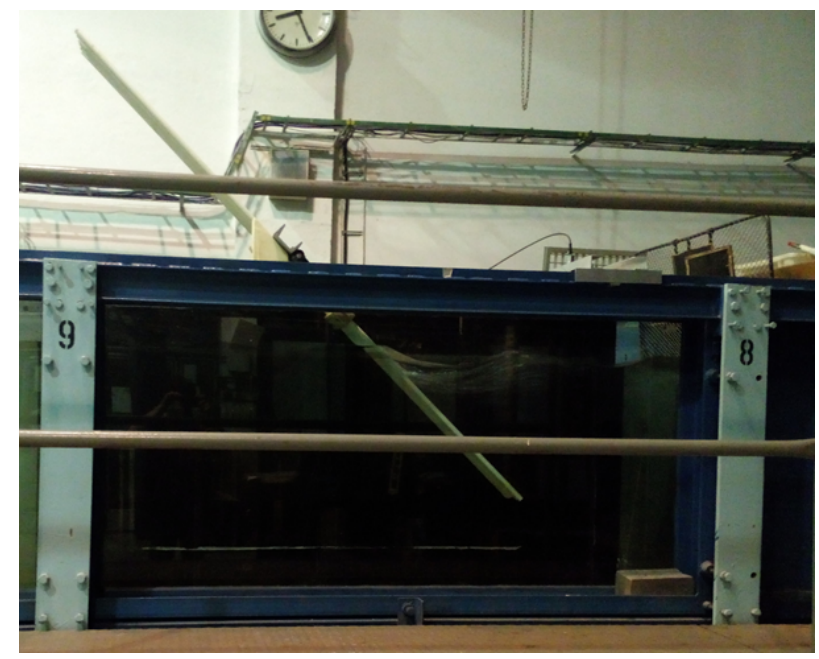

Figure 5. Placement of the model in the laboratory.

Furthermore, it was necessary to produce a swing joint with the possibility of fitting individual screen bars of different lengths and especially different diameters and shapes. The swing joint can be fitted with any number of rods depending on how the hydraulic trough is narrowed. The whole model was supplemented by a high-speed camera suitable for capturing the effect of water flow on individual rods so that we can slow down the shots and then evaluate them. 


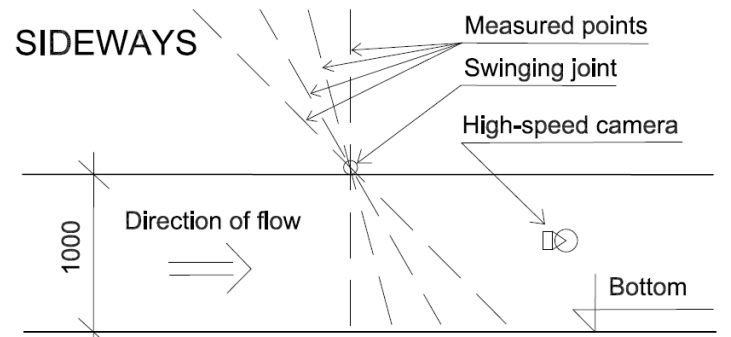

\section{FLOOR PLAN}

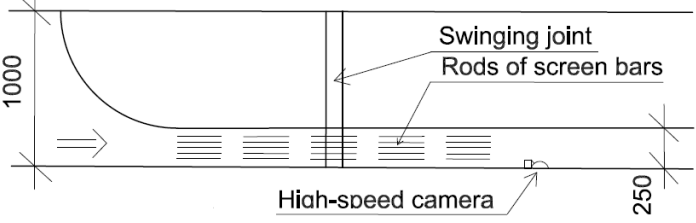

Figure 6. Diagram of the location in the hydraulic trough [7.

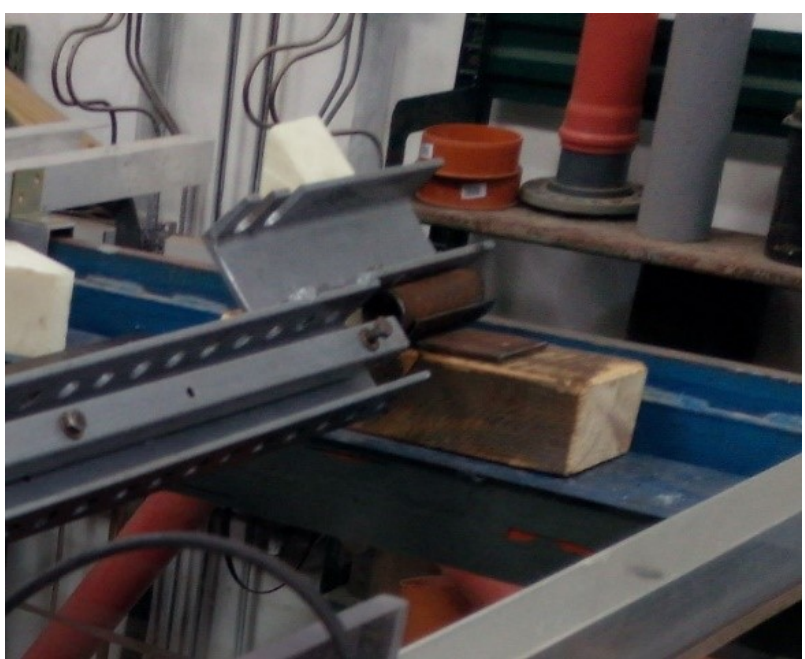

FigURE 7. Swinging joint.

\subsection{Measurement procedure}

There are necessary mechanical properties that must be taken into account, such as flexural strength (that is an important feature when the self-cleaning bars are clogged with impurities, which increases the pressure losses and the forces acting on the self-cleaning bars), surface roughness (smooth surface prevents dirt from settling on the self-cleaning bars and clogging) and oscillation of the free ends of the self-cleaning bars in the stream (vibration results in a self-cleaning function of the self-cleaning bars, oscillation releases already settled impurities).

The physical model investigates the behaviour of individual self-cleaning bars in the flow corresponding to the real flow in the sewer system. During the measurement, bars of different diameters and different elliptical shapes are gradually tested depending on their length and angle of inclination to the current. All measurements are taken by a high-speed camera, then decelerated 8 times and analysed in order to subtract the number of oscillations per second of the

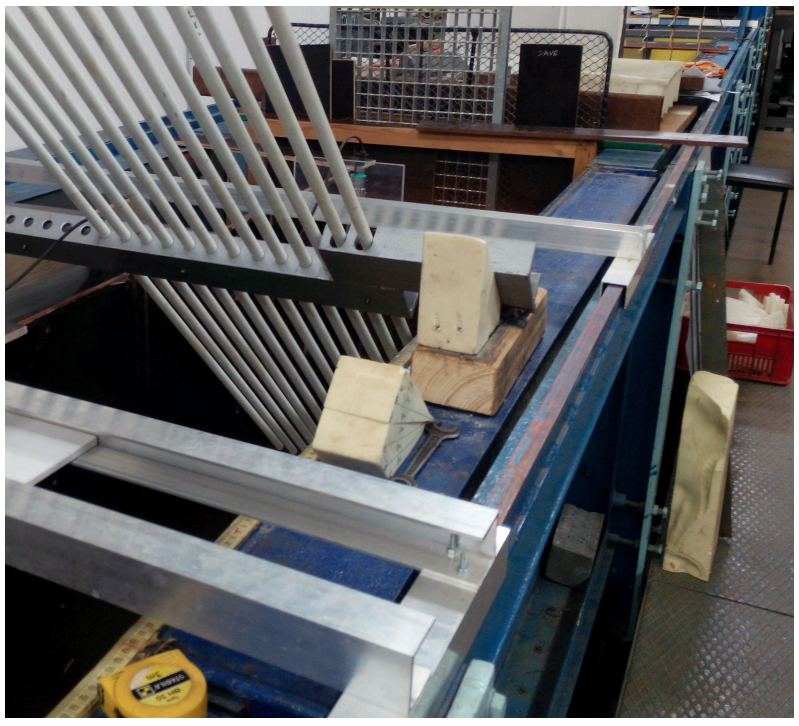

Figure 8. Attachments for adjusting the angle of inclination of the screen bars.

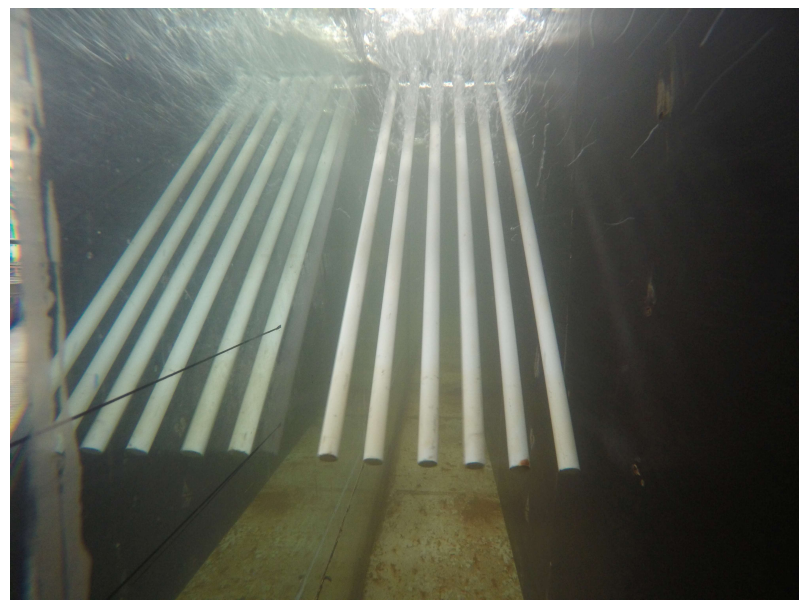

Figure 9. Footage from a high speed camera.

free end of the rod and measure the oscillation of the rods and to determine whether adjacent bars collide during the oscillation. During the measurement, profiles that achieve the highest possible oscillations per second (due to the support of the self-cleaning process) and at the same time achieve such a fluctuation that there is no collision of individual screen bars and their mechanical damage, are searched. [4, 8]

A total of 135 states were measured at a flow rate from $79 \mathrm{l} / \mathrm{s}$ to $200 \mathrm{l} / \mathrm{s}$ and flow velocities from $v=0.8 \mathrm{~m} / \mathrm{s}$ to $0.9 \mathrm{~m} / \mathrm{s}$, according to the used narrowing of the hydraulic trough so that the screen bars are flooded at the selected length always up to the joint or to a movable attachment guaranteeing a firm anchoring of the rods at a given length.

The individual rods are always axially spaced $36 \mathrm{~mm}$ apart in the model. The shape of the rods is circular and elliptical with different dimensions (see Fig. 11. The length of the rods ranges from $50 \mathrm{~cm}$ to $140 \mathrm{~cm}$ (longer rods do not fit in the trough). The angle of inclination of the self-cleaning screen bars was grad- 


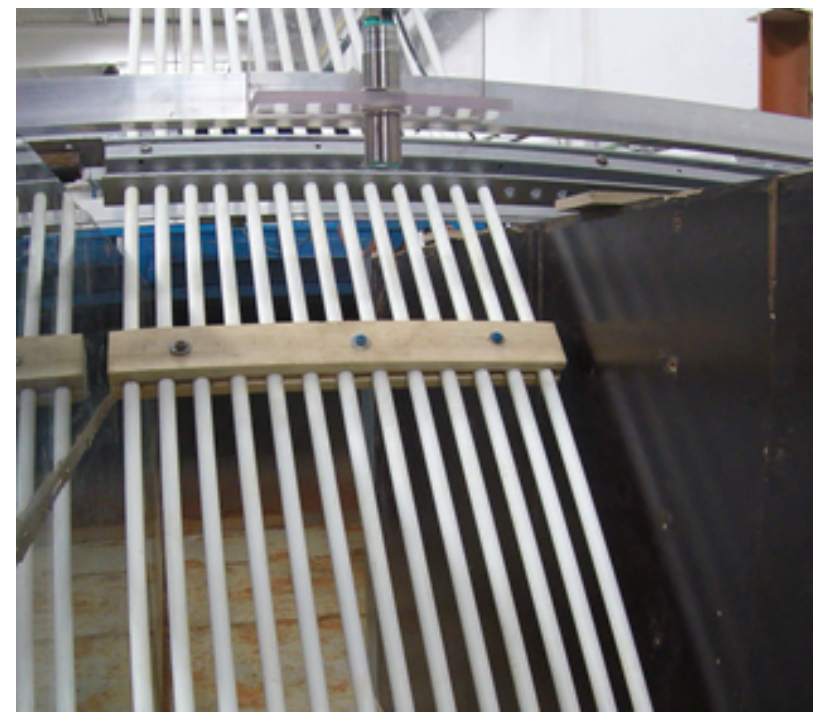

FiguRE 10. Movable attachments guaranteeing free length and rotation of the screen bars rods.

ually changed by $15^{\circ}$ from the vertical state up to an inclination of $45^{\circ}$. All 135 states were captured by a high-speed camera, where the recordings were slowed down by $8: 1$ and subsequently, the number of oscillations of individual rods per second and the distance of their oscillation in mm were determined from them.

\section{Results AND THEIR DisCUSSION}

The following graph (Fig. 12) shows the effect of oscillation on the swing distance perpendicular to the flow direction. This graph considers the oscillation and oscillation values of screen bars of round profiles and elliptical profiles, the longitudinal axis of which is parallel to the flow axis.

The colour distribution of the measured results is according to the inclinations of the screen bars. A blue range of colours is chosen for a $45^{\circ}$ inclination and green for a $60^{\circ}$ inclination. The inclinations of the bars at $75^{\circ}$ are in the red colour scale and the bars in the vertical $\left(90^{\circ}\right.$ inclination) are marked with a yellow colour scale.

From the graph, it can be observed that the oscillation most often reaches values of $7-12 \mathrm{~Hz}$ with fluctuations up to $20 \mathrm{~mm}$. The limit values of swing above $35 \mathrm{~mm}$, which can already cause collisions of the free ends of individual rods, are represented only minimally, mainly for rods with small inclinations $\left(45^{\circ}\right.$ and $60^{\circ}$ ). With inclinations of $75^{\circ}$ and $90^{\circ}$, there is a risk of collisions only at oscillations above $12 \mathrm{~Hz}$ and these occur minimally. The effect of oscillation $(\mathrm{Hz})$ on the swing distance $(\mathrm{mm})$ is, therefore, observed, but it is not linear.

\section{VERIFICATION OF THE \\ SELF-CLEANING EFFECT OF RODS OF SWINGING SCREEN BARS}

After completing a series of measurements of mechanical features of oscillating self-cleaning screen bars, I verified the self-cleaning effect of all types of screen bars (except elliptical ones perpendicular to the current - due to the collision of individual rods, their use in operation is incompatible). I used real pollution, which occurs in sewage systems (textiles, rags, shoes, condoms, sanitary towels and tampons, paper handkerchiefs and cleansing pads).

I placed the aesthetic dirt in the hydraulic trough in the stream so that the stream applied it to the screen bars and with the help of slow-motion video recordings, I verified how the dirt adheres to the individual rods of the self-cleaning screen bars and especially how it is subsequently released from them. The main part of the interest was to verify the behaviour of the screen bar rods at the end of the rain event, when there will be a gradual decrease in the increased flow until it returns to a rainless state, when the CSO stops falling. In this state, only a part of the free ends of the screen bars is immersed, which gradually completely emerge from the falling water. In the initial phase, it was clear that when the rods of the lengths 5 to $10 \mathrm{~cm}$ are immersed, they significantly oscillate and subsequently release all the remaining impurities. 4 types of bars were verified, with each measurement being repeated 3 times. The measurement always started with the level reaching flooding of the swinging joint, followed by a gradual decrease of the level to zero.

During the experiments with the flooding of the rods of the screen bars up to the swinging joint, pollution of larger dimensions (sanitary towels, condoms, rags and footwear) was caught and subsequently shifted towards the bottom of the trough in almost all cases. While the contamination of smaller dimensions (women's tampons and cleansing pads) in $50 \%$ of cases passed between individual rods without being captured. However, after some time (usually in the order of tens of seconds, max. $2-3$ minutes), the captured pollution of smaller dimensions was always released in the direction of flow, or slid along the bars towards the bottom of the hydraulic trough in the direction of the flow.

Fig. 15 shows the process of the self-cleaning effect of swinging screen bars, which occurs during the simulation of the ending rain event, when a gradual decrease in the level in the CSO causes a significant oscillation of the free ends of the rods of screen bars from which all remaining impurities are released. This effect was observed in all experiments with all types of rods, after the end of all experiments, no impurities remained on the rods. See more v. videos attached to the CD.

During the experiment, it was clearly proven that the self-cleaning effect of the CSO Hobas Chamber 


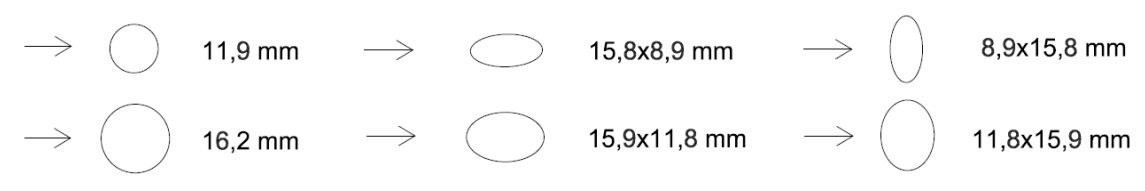

Figure 11. Diameters and shapes of tested rods.

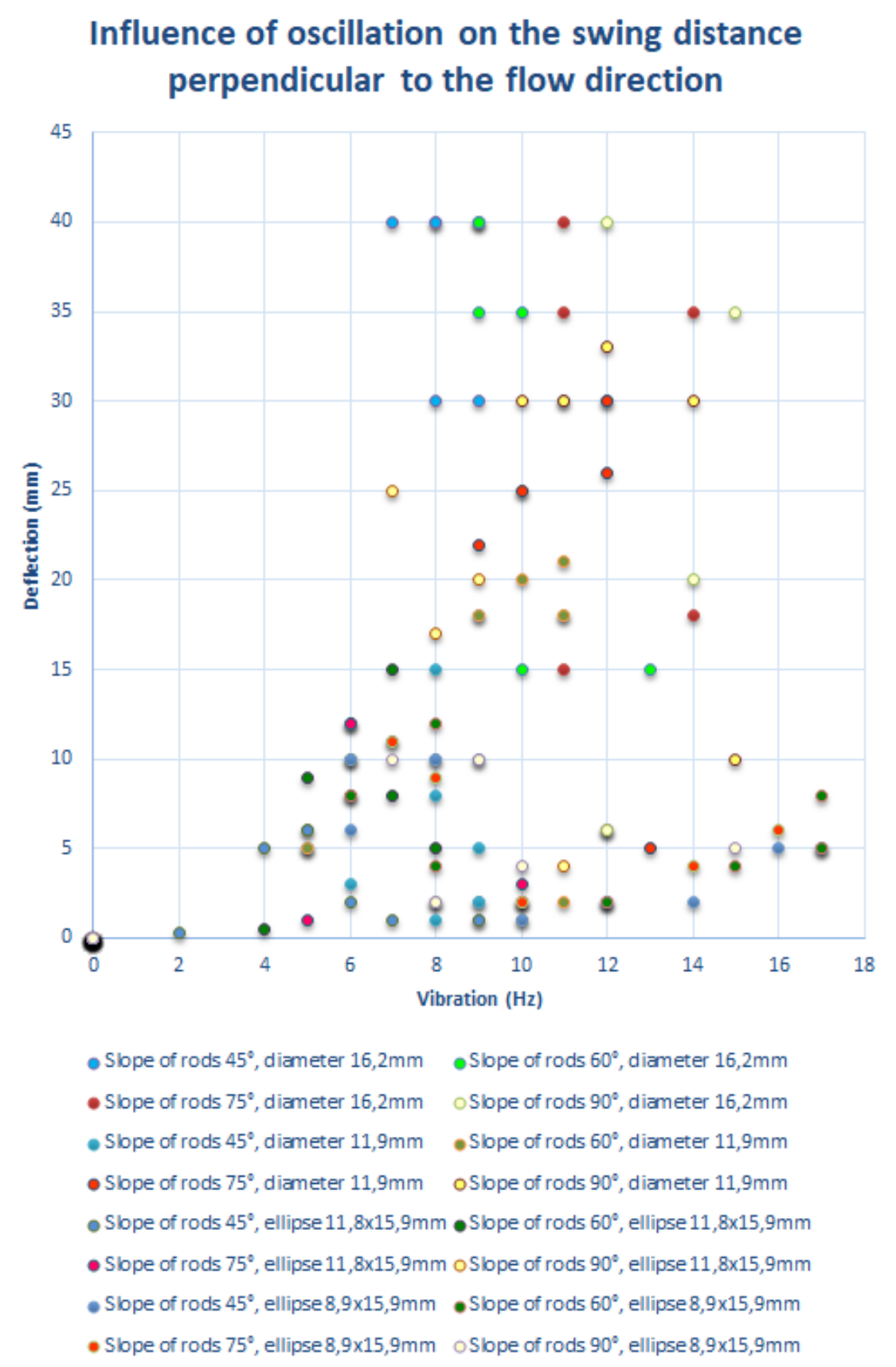

FIGURE 12. Influence of oscillation. 


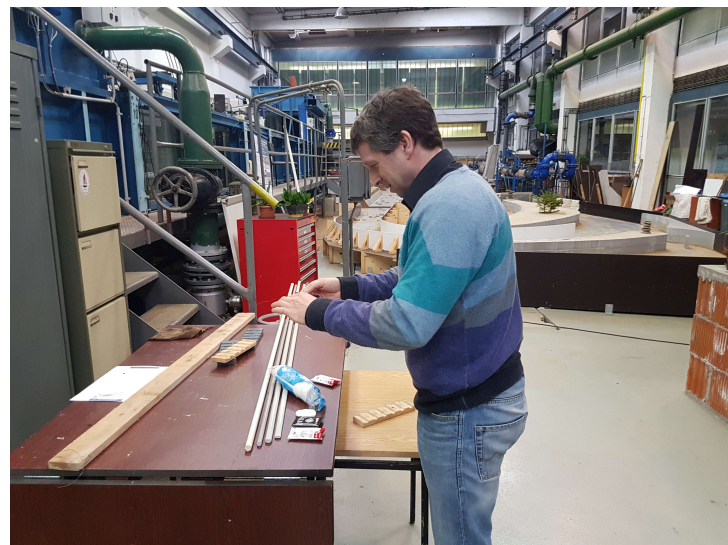

FiguRE 13. Preparation of aesthetic pollution for experiments.

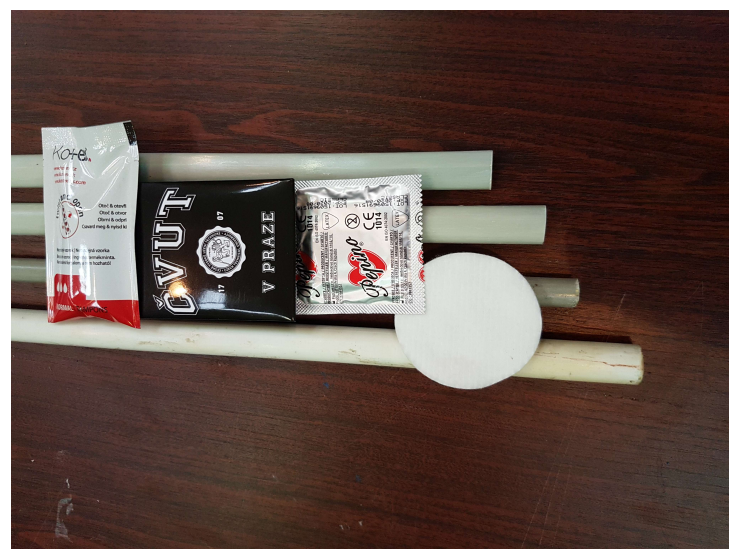

Figure 14. Condoms and tampons.

swinging screen bars occurs and that it is $100 \%$ effective.

\section{Conclusion of measurement of SWING SCREENG BARS}

During the research of mechanical properties of selfcleaning screen bars, it was found that both types of elliptical screen bars placed perpendicular to the current achieve such a large fluctuation in both directions that they are unusable due to a mutual collision of individual rods. During the experiments, the chosen composite material proved to be very suitable, there was no damage or wear to any of the screen bars rods, or roughening of their surface and subsequent possible reduction of the self-cleaning effect, which proved to be very effective especially when the water level simulates the end of a rain event.

Round rods have a very similar number of oscillations in both diameters (11.9 and $16.2 \mathrm{~mm}$ ). Nevertheless, from a swing point of view, $11.9 \mathrm{~mm}$ rods are more suitable because they did not collide during any measurements. Whilst in the case of the $16.2 \mathrm{~mm}$ rods, there were collisions of the free ends at rod lengths over $80 \mathrm{~cm}$.

Elliptical screen bars located with their longitudinal axis in the direction of the flow clearly appear to be the most suitable. With a rod length of up to $1 \mathrm{~m}$, the profile rods of $11.8 / 15.9 \mathrm{~mm}$ reach higher oscillations and satisfactory swing values, above $1 \mathrm{~m}$, profile rods of $8.9 / 15.9 \mathrm{~mm}$ reach higher oscillations and satisfactory swing values. When the screen bars are placed longitudinally with the current swing, there is no mutual collision of the free ends of the bars at all their lengths.

In general, the speed of movement of the free oscillating end of the rods increases with the length of the rod $\rightarrow$ higher speed of movement helps the self-cleaning effect of the screen bars.

For the project of swinging screen bars with a selfcleaning function, I therefore recommend elliptical rods located with their longitudinal axis in the direction of the flow. I propose a profile of $11.8 / 15.9 \mathrm{~mm}$ for screen bars rod lengths up to $1 \mathrm{~m}$, and a profile of $8.9 / 15 / 9 \mathrm{~mm}$ for screen bars rod lengths over $1 \mathrm{~m}$. [7]

\section{Application of measurement RESULTS IN PRACTICE}

The obtained results have already been partially applied in practice. The determined loss coefficients were entered into the design table for the calculation of capacitive flow in the CSO Hobas Chamber. According to the proposed optimization, CSOs have already been designed and installed (Germany 2014, Castel San Pietro, Kežmarok 2017, Slovakia 2017).

The conclusions of the measurements obtained during the research of the mechanical properties of the swinging self-cleaning screen bars were supplied by the manufacturer CSO Hobas Chamber (formerly HOBAS-CZ, now it is the company Amiblu Holding GmbH through the subsidiary Amiblu Technology AS). According to the recommended designs resulting from the work, the swinging screen bars with a self-cleaning function will be optimized during the production of the a CSO Hobas Chamber.

As it is indicated by the development of laws and decrees in the Czech Republic, as well as in the world, in the future, it will be necessary to choose the right configuration of the CSO by measuring the flow in order to calculate the fee for discharged lightened water falling from the CSO. According to the above information, the resulting fee should be reduced by a coefficient based, inter alia, on the degree of pre-treatment of light waters. The obtained results helped to optimize the CSO Hobas Chamber in terms of functionality and probably, in the future, in terms of financial savings for fees for the discharge of wastewater during the operation of the CSO.

\section{ACKNOWLEDGEMENTS}

The contribution was supported by the project Student Grant Competition SGS13 / 173 / OHK1 / 3T / 11 and TAČR TE02000077 Smart Regions - Buildings and Settings Information Modeling, Technology and Infrastructure for Sustainable Development. 

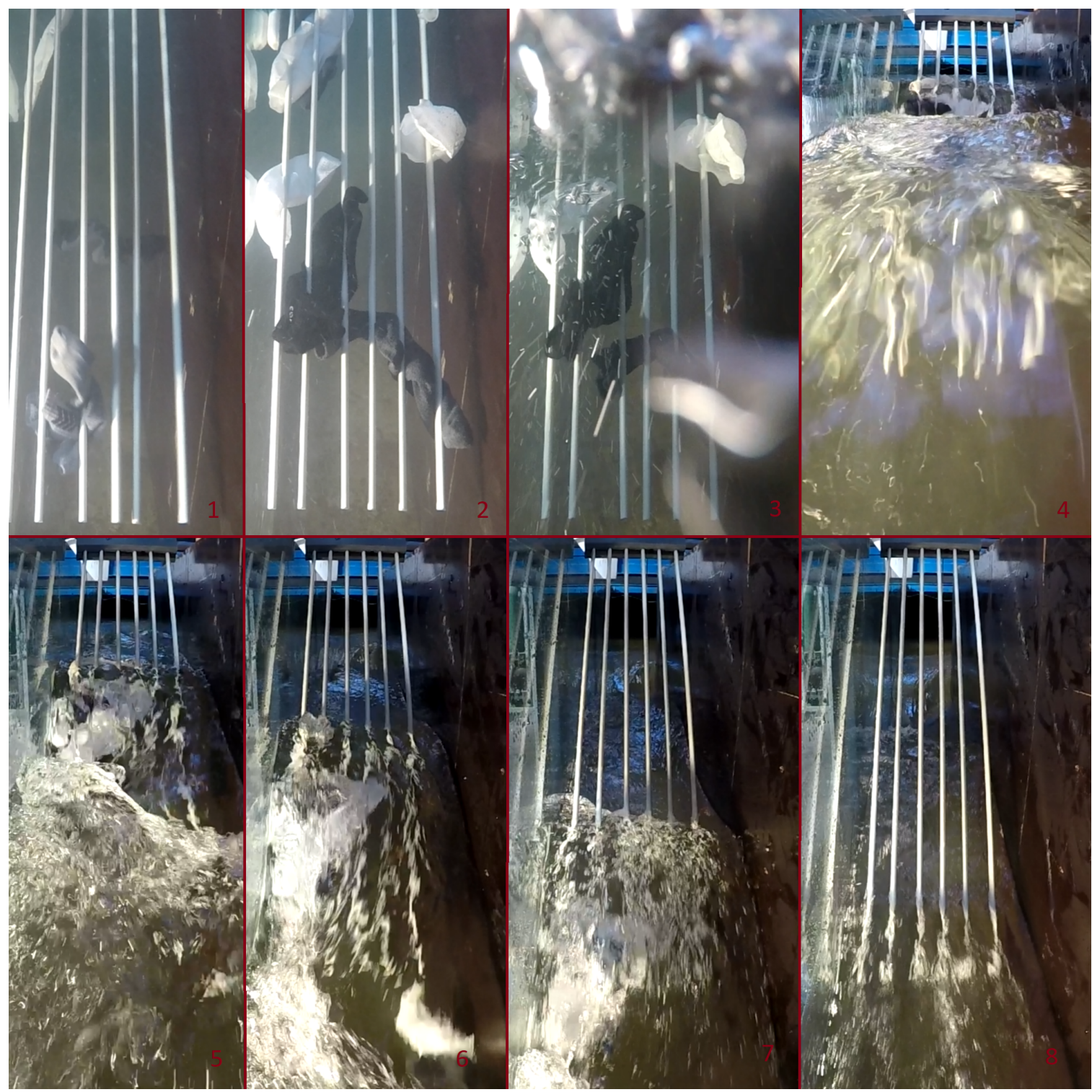

FiguRE 15. Self-cleaning effect of CSO Hobas chamber swinging screen bars (time-lapse photo from the video).

\section{REFERENCES}

[1] J. Prochazka, J. Pollert, O. Svanda. Swinging self-cleaning screen bars the tube Hobas CSO Chamber, their physical properties and design. In G. Mannina (ed.), New Trends in Urban Drainage Modelling, pp. 136 - 140. 2019. DOI:10.1007/978-3-319-99867-1_24.

[2] T. Hlavínek. Hospodaření s deštovými vodami v urbanizovaném území. ARDEC, Brno, 2008.

[3] D. Komínková, J. Nábělková, T. Vitvar. Effects of combined sewer overflows and storm water drains on metal bioavailability in small urban streams (Prague metropolitan area, Czech Republic). Journal of Soils and Sediments 16(5):1569 - 1583, 2016. DOI:10.1007/s11368-015-1327-8.

[4] J. Pipa. Optimalizace návrhu odlehčovacích komor na jednotné stokové síti. Bachelor's thesis, Brno University of Technology, Brno, 2012.
[5] K. Soukupová, J. Nábělková, J. Pollert, P. Chmatal. Assessment of separation efficiency of reconstructed combined sewer overflow in debr (czech republic). In G. Mannina (ed.), New Trends in Urban Drainage Modelling, pp. 224 - 229. 2019. DOI:10.1007/978-3-319-99867-1_37.

[6] T. Durčo. Modelová studie tlakových ztrát „Hobas CSO Chamber. Master's thesis, CTU in Prague, Prague, 2013.

[7] J. Procházka. Optimalizace účinnosti odlehčovacích komor. Ph.D. thesis, CTU in Prague, Prague, 2020.

[8] J. Pollert. Trubní odlehčovací komora jako ekologicko-ekonomické řešení. Vodni hospodářství 58(2):36 - 39, 2008. 